
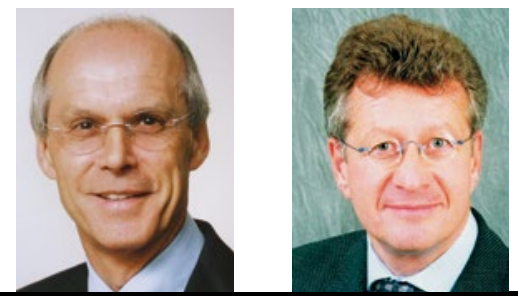

\title{
Warum hat meine Patientin gelbe Hände?
}

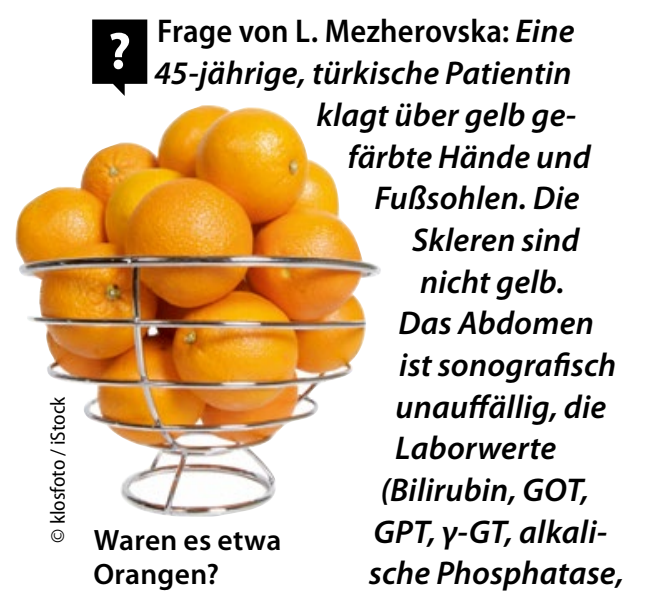

Amylase, Lipase, kleines Blutbild, TSH) im Normbereich, lediglich die TPO-AKKonzentration ist mit $113 \mathrm{U} / \mathrm{ml}$ erhöht. Karotten isst sie nicht.

!

MMW-Experte FüeßI: Dazu fällt mir nur eine Hypercarotinämie ein. Ich habe selbst eine völlig gesunde Patienten erlebt, die pro Tag $4 \mathrm{~kg}$ Orangen aß und ein gelbes Hautkolorit besonders im Bereich der Handlinien hatte. Bei türkischen Frauen sind auch Einreibungen der Hände z. B. mit Henna beliebt. Hier liegt wohl keine Erkrankung vor.
I MMW-Experte Stiefelhagen: Bei dieser Patientin dürfte eine Störung des Beta-Carotin-Metabolismus vorliegen, denn es liegt ja keine erhöhte $\mathrm{Zu}$ fuhr vor. Das Beta-Carotin wird physiologisch durch eine Monooxygenase (BCO) in Vitamin A umgewandelt. Bei diesem Enzym gibt es einen genetischen Polymorphismus, die Aktivität ist also bei bestimmten Personen vermindert, sodass weniger Beta-Carotin abgebaut und mehr in der Haut abgelagert wird. Einen Krankheitswert hat diese Störung aber nicht.

\section{Rheumatoide Arthritis}

\section{Stören Kortikoide den Anti-CCP-Titer?}

? Frage von Ralf Übelacker: Kann der generelle Nachweis bzw. die Titerhöhe der Antikörper gegen zyklische citrullinierte Peptide (Anti-CCP) in der Rheumadiagnostik durch eine vorangegangene systemische oder lokale Kortikoidtherapie beeinflusst werden?

MMW-Experte Stiefelhagen: Nein. Anti-CCP sind wie auch die Rheumafaktoren keine Entzündungsparameter, sondern serologische bzw. immunpathogenetische Marker. Ihr Titer wird durch therapeutische Maßnahmen nicht beeinflusst, weshalb sie sich auch nicht für die Verlaufs- und Therapiekontrolle eignen. Nebenbei bemerkt haben AntiCCP keine 100\%ige Sensitivität, sind also nicht immer bei rheumatoider Arthritis nachweisbar.

!

MMW-Experte FüeßI: Antikörper gegen citrullinierte Peptide/Proteine und gegen zyklische citrullinierte Peptide, die mit dem Sammelnamen ACPA bezeichnet werden, weisen eine überragende Spezifität von fast $100 \%$ für die rheumatoide Arthritis auf, bei allerdings deutlich geringerer Sensitivität von $65-70 \%$. CCP-Autoantikörper ha- ben einen hohen prädiktiven Wert für einen erosiven Verlauf der Erkrankung und können bereits in der Frühphase, bis zu zehn Jahre vor Beginn der klinischen Symptomatik auftreten. Jeder Patient mit einem positiven Befund sollte also beraten und beobachtet werden.

Unter Therapie korreliert die Titerhöhe der ACPA nicht mit dem Krankheitsverlauf, sodass sie nicht wie der Rheumafaktor zur Verlaufskontrolle geeignet sind. Zwar wurde in einigen Studien ein Abfall der ACPA-Titer unter immunsuppressiver Therapie beschrieben, doch bilden diese keine klare Evidenz. 